\title{
Exercise training regulates angiogenic gene expression in white adipose tissue
}

\author{
Hyuek Jong Lee* \\ Institute of Zoology, Chinese Academy of Sciences, Beijing, China
}

White adipose tissue (WAT) expansion is associated with angiogenesis. Although, activation of lipolysis by exercise induces adipocyte hypotrophy and reduction of fat mass, it is poorly understood whether exercise regulates angiogenesis by altering angiogenic gene expression in WAT. Therefore, the purpose of this study was to evaluate the effect of 6 weeks voluntary wheel running exercise on angiogenic gene expression in adipose tissues. Male C57BL/6J mice performed voluntary wheel running for 6 weeks. At $24 \mathrm{hr}$ after the last exercise training, tibialis anterior (TA), soleus (Sol), epididymal WAT (eWAT), inguinal WAT (iWAT), and brown adipose tissue (BAT) were isolated and then the expressions of vascular endothelial growth factor A (VEGFA), angiopoietin1 (Ang1), Ang2, platelet-derived growth factor $B$ (PDGF-B) and their corresponding receptors were analyzed by reverse transcription-polymerase chain reaction. In skeletal muscles, VEGFA expression was upregulated in TA and Sol and PDDGF-B expression was increased in Sol after exercise training. In eWAT, the expressions of VEGFA and Flk-1 were dramatically downregulated, whereas Ang2 and PDGFR $\beta$ was upregulated after exercise training. In iWAT, VEGF expression was increased with the downregulation of Ang1. However, there was no alteration of any of these genes in BAT. These results suggest that angiogenic gene expression is altered by exercise training and voluntary wheel running regulates VEGFA, Ang1, and Ang2 expressions in a fat depot specific manner.

Keywords: Voluntary wheel running, White adipose tissue, Vascular endothelial growth factor, Angiopoietin, Platelet-derived growth factor

\section{INTRODUCTION}

As an endocrine organ, white adipose tissue (WAT) regulates systemic energy homeostasis. Since WAT has a strong plasticity, its expansion according to overnutrition is associated with metabolic diseases. WAT expansion is highly depends on angiogenesis that is defined as a formation of new blood vessels from pre-existing vasculature. When adipose tissues are expanded, adipogenesis is followed by the generation of dense vascular network (DVN) in rodents and introduction of antiangiogenic agents such as soluble vascular endothelial growth factor receptor 2 (Flk-1) or vascular endothelial growth factor A (VEGFA) inhibitor prevents the formation of DVN, resulting in the enhancement of antiadipogenic effects (Cho et al., 2007). Additionally, an angiogenic inhibitor TNP-470 treated ob/ob mice reduced body weight gain by diminishing adiposity (Rupnick et al., 2002), supporting that an- giogenesis is accompanied with adipogenesis.

Angiogenesis is induced by angiogenic factors and major angiogenic factors expressed from WAT include VEGF, angiopoietin (Ang) and platelet-derived growth factor (PDGF). VEGF family has VEGFA, VEGFB, VEGFC, and VEGFD. VEGFA, the predominant form, has five different isoforms $\left(\mathrm{VEGF}_{121}, \mathrm{VEGF}_{165}\right.$, $\mathrm{VEGF}_{189}$, and $\mathrm{VEGF}_{206}$ ) and binds to its receptor VEGFR1 (Flt-1) and VEGFR2 (Flk-1). Since VEGFA induced Flk-1 activation is the key regulator of endothelial cell survival and growth (Ferrara et al., 2003), VEGFA haplodeficient mouse shows a lethal phenotype in embryonic days 11-12 due to impairment of blood vessel development and deficiency of red blood cell in blood island of york sac (Carmeliet et al., 1996; Ferrara et al., 1996). In addition, VEGFA deletion in perineonatal mouse using cre-loxP system brings the defect of tissue and vascular developments (Gerber et al., 1999). Similar with VEGFA deficient phenotype, VEGFR2
${ }^{*}$ Corresponding author: Hyuek Jong Lee (D) https://orcid.org/0000-0001-5477-5133 Key Laboratory of Animal Ecology and Conservation Biology, Institute of Zoology, Chinese Academy of Sciences, Beijing, 100101, China

Tel: +86-106-480-7098, Fax: +86-106-480-7099, E-mail: Hyuekjong.lee@gmail.com Received: January 7, 2018 / Accepted: February 11, 2018
This is an Open Access article distributed under the terms of the Creative Commons Attribution Non-Commercial License (http://creativecommons.org/licenses/by-nc/4.0/) which permits unrestricted non-commercial use, distribution, and reproduction in any medium, provided the original work is properly cited. 
deficient mouse also fails to vascular development by impairing differentiation of endothelia cell and hematopoietic stem cell (Shalaby et al., 1995). Ang family has Ang1, Ang2, and Ang3. While Ang1 is expressed on smooth muscle cells, pericytes and fibroblast, Ang2 is almost exclusively expressed from endothelial cells. Both Ang1 and Ang2 bind to their receptor, TEK tyrosine kinase receptor 2 (Tie2) that is expressed on endothelial cell and macrophagy (Fagiani and Christofori, 2013). As the major function of Ang1 is to regulate vascular remodeling and maturation, Ang1 or Tie2 deletion mice are lethal (Suri et al., 1996). Moreover, Ang1 enhances integrity of vasculature by recruiting pericytes into blood vessel, therefore, Ang1 overexpression mouse increases endothelial cell quiescent (Cho et al., 2005; Suri et al., 1998). Also, exogenous Ang1 treatment is beneficial for the recovery from injured tissues by inducing angiogenesis (Chae et al., 2000; Jung et al., 2009; Park et al., 2009; Shin et al., 2010; Smith et al., 2012). In contrast to Ang1, Ang2 acts as an antagonist of Ang1. Ang2 is able to bind integrin and then prevents anti-inflammatory function of Ang1 (Felcht et al., 2012; Gale et al., 2002). In the same context, Ang2 overexpression brings embryonic lethality by inhibiting vascular development, which is shown in Ang1 or Tie2 deficient mouse (Maisonpierre et al., 1997; Suri et al., 1996). Interestingly, plasma Ang2 concentration is upregulated in inflammation and Type2 diabetes (Fiedler et al., 2006; Li et al., 2015), meaning that inflammation might be a key regulator of Ang2 expression.

PDGF family is composed of five dimeric isoforms, PDGF-AA, PDGF-AB, PDGF-BB, PDGF-CC, and PDGF-DD. PDGF family bind to PDGF receptor (PDGFR)a or PDGFR $\beta$. Specifically, PDGF-BB that is important stimulus for the differentiation of embryonic stem cell into endothelial cell in developmental stage and it regulates proliferation, migration and tube formation of endothelial cell (Lange et al., 2009). In adults, PDGF-BB that is mainly expressed from endothelial cell is involved in the recruitment of PDGFR $\beta^{+}$pericytes and enhances blood vessel stability (Levéen et al., 1994; Soriano, 1994).

Angiogenesis in adipose tissue is mediated by angiogenic factors. Although adipose tissue specific VEGFA deleted mouse reduces fat mass under high fat diet condition, it causes insulin resistance since lipid designated to adipose tissue is accumulated in other tissues such as liver and skeletal muscle. In the opposite way, adipose tissue specific overexpression of VEGFA increases insulin sensitivity by diminishing local hypoxia in adipose tissue (Sung et al., 2013). Ang1 and Ang2 expressions are also altered depending on the augmentation of adipose tissues (An et al., 2017; Dallabri- da et al., 2003). In addition, whole body PDGFR $\beta$ deficiency improves adipocity and insulin sensitivity in high fat diet induced obese mouse (Onogi et al., 2017).

Exercise has been shown to modulate angiogenic gene expression in heart and skeletal muscle (Erekat et al., 2014; Gustafsson et al., 1999; Lloyd et al., 2003; Trenerry et al., 2011). However, it has not been extensively investigated whether exercise regulates angiogenic gene expression in adipose tissue. To interrogate the effect of exercise training on angiogenic gene expression, mice were performed voluntary wheel for 6 weeks and then the mRNA levels of VEGFA, Angs, PDGF-B and their receptors were analyzed in this study.

\section{MATERIALS AND METHODS}

Mice

Male C57BL/6J mice at 5 weeks of age were purchased from Central Lab. Animal Inc. (Seoul, Korea). Mice were housed in an environmentally controlled facility certified by the Office of Laboratory Animal Welfare with a 12-hr light/dark cycle and had free access to food and water.

All animal experiments were proved by The Institutional Animal Care and Use Committee of Dongguk University (IACUC2017-017).

\section{Exercise protocol}

After 2 weeks of acclimation, C57BL/6J male mice at 7 weeks of age were randomly divided into two groups: a sedentary control group and a voluntary wheel running exercise group $(\mathrm{n}=8$ in each group). Mice in exercise group were housed individually in wheel cage (Nalgene) where mice are able to run voluntarily on the wheel all the time. The wheel revolution was automatically counted and the average of running distance for each mouse was calculated at the end of 6 weeks. The average distance of exercise group was $4.96 \pm 2.77 \mathrm{~km} /$ day. Age and sex matched control mice were housed individually in cage without wheel. After 6 weeks of training, mice were sacrificed $24 \mathrm{hr}$ after the last exercise training.

\section{Tissue isolation}

For the analysis of angiogenic gene expression, tibialis anterior (TA), soleus (Sol), epididymal WAT (eWAT), inguinal WAT (iWAT), and brown adipose tissue (BAT) from mice in control and exercise groups were isolated and then were snap frozen in liquid nitrogen and stored at $-80^{\circ} \mathrm{C}$ for further analysis. 


\section{RT-PCR}

Total RNA was extracted from TA, Sol, eWAT, iWAT, and BAT collected from control and exercise groups using TRIzol isolation reagent (Invitrogen, Carlsbad, CA, USA) under the manufacturer's instructions. RNA concentration was spectrophotometrically determined using NanoDrop (Thermo Fisher Scientific, Waltham, MA, USA). Using murine leukaemia virus reverse transcriptase and oligo (dT)16 primer, two micrograms of tissue RNAs were reverse transcribed. The resulting cDNAs from tissue samples were assayed in duplicate. Reverse transcription-polymerase chain reaction (RT-PCR) was conducted using $2 \mathrm{X}$ SYBR

Table 1. Sequences of primers for reverse transcription-polymerase chain reaction

\begin{tabular}{|c|c|}
\hline Gene & Primer sequences $\left(5^{\prime}-3^{\prime}\right)$ \\
\hline \multirow[t]{2}{*}{ VEGFA } & F: CACTTCCAGAAACACGACAAAC \\
\hline & R: TGGAACCGGCATCTTTATCTC \\
\hline \multirow[t]{2}{*}{ Flk-1 } & F: TGGTCTTCTGTGAGGCAAAG \\
\hline & R: GGCTCAGGACCACATCATAAA \\
\hline \multirow[t]{2}{*}{ Ang1 } & F: ACCTGCCCATTCCAGTATC \\
\hline & R: GAGTCTTAGGCACCTTCTACC \\
\hline \multirow[t]{2}{*}{ Ang2 } & F: GGCTCTCACTGATGGACTTATT \\
\hline & R: CTGCСАСАТТСТСТСТСТСТT \\
\hline \multirow[t]{2}{*}{ Tie2 } & F: TITGCCCTCCTGGGTTATG \\
\hline & R: CTTCTGGTCCACTACACCTTC \\
\hline \multirow[t]{2}{*}{ PDGF-B } & F: GAGTGTGGGCAGGGTATIT \\
\hline & R: GAATCAGGCATCGAGACAGAC \\
\hline \multirow[t]{2}{*}{ PDGFR $\beta$} & F: GTTGTTGCTGTCCGTGTATG \\
\hline & R: AAGGTGCTGGAGATGTTGAG \\
\hline \multirow[t]{2}{*}{ GAPDH } & F: AACAGCAACTCCCACTCTTC \\
\hline & R: CCTGTTGCTGTAGCCGTATT \\
\hline
\end{tabular}

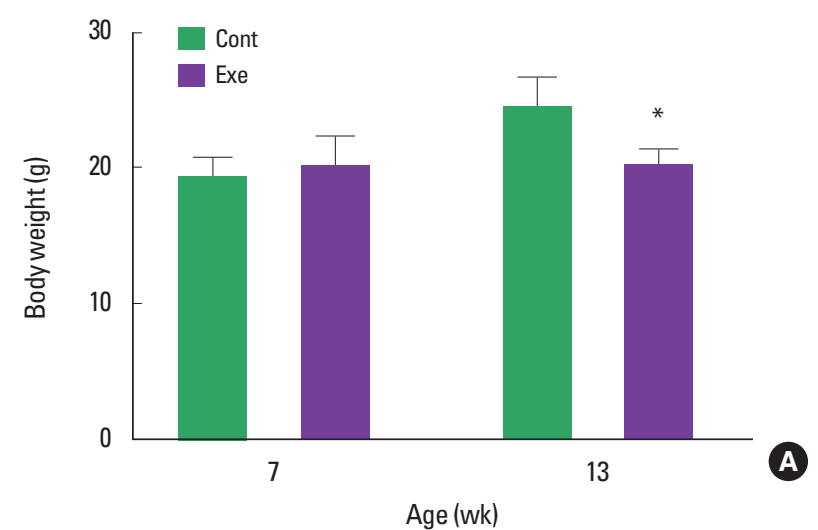

green PCR master mix on a real-time PCR system (Applied Biosystems, Waltham, MA, USA). Gene expression data were normalized to the housekeeping gene GAPDH and analyzed using the delta delta cycle threshold method $\left(\Delta \Delta C_{\mathrm{t}}\right)$. Primer sets are described in Table 1.

\section{Statistical analysis}

Results are expressed as means \pm standard deviation. The normality was confirmed with the Shapiro-Wilk test and then, depending on its outcome, data were analyzed using Student $t$-test or the Mann-Whitney $U$-test. Statistical significance was set at $P<0.05$.

\section{RESULTS}

\section{Exercise training reduces WAT mass}

To identify the change of body weight and adipose tissue weight by exercise training, body weight were measured before and after exercise training and adipose tissue weight were measured after exercise training. After 6 weeks of voluntary wheel running exercise, the body weight was decreased only in exercise group (Fig. 1A). And the fat weight was reduced $40 \%$ in eWAT $(220.90 \pm 39.32 \mathrm{mg}$ vs. $87.32 \pm 40.53 \mathrm{mg}, P<0.001)$ and iWAT $(146.85 \pm 26.45 \mathrm{mg}$ vs. $78.74 \pm 23.02 \mathrm{mg}, P<0.01)$ respectively after 6 weeks of training. However, BAT weight was comparable between groups $(57.30 \pm 8.92 \mathrm{mg}$ vs. $55.70 \pm 14.60 \mathrm{mg}, P>0.05)$.

\section{VEGFA expression is reduced in WAT after exercise training}

Since VEGFA is one of the strongest angiogenic factors, its expression was analyzed in TA, Sol, eWAT, iWAT, and BAT with

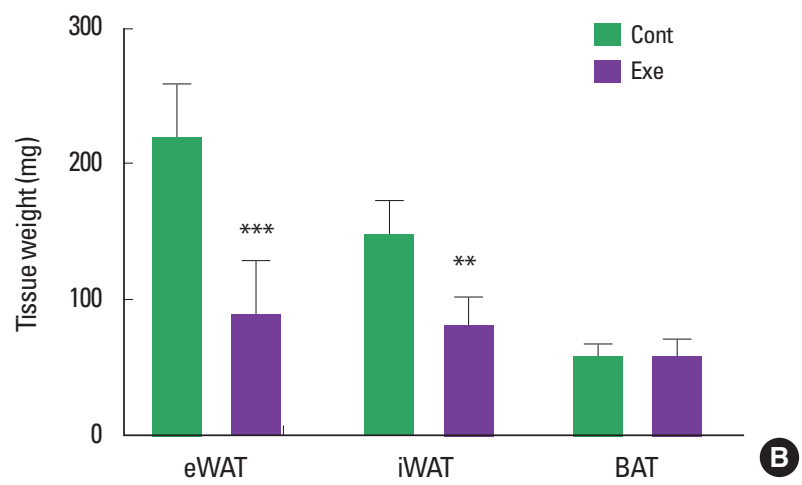

Fig. 1. Body weight and fat weight change after exercise training. (A) Body weights of mice at 7 and 13 weeks of age were measured. (B) The weights of adipose tissues were measured after 6 weeks of exercise training. Bars represent the means and error bars represent standard deviation $(n=8)$. Cont, control group; Exe, exercise group; eWAT, epididymal white adipose tissue; iWAT, inguinal white adipose tissue; BAT, brown adipose tissue. ${ }^{*} P<0.05,{ }^{* *} P<0.01,{ }^{* * *} P<0.001$ vs. Cont. 
RT-PCR. Interestingly, the expression level of VEGFA in Sed was higher in eWAT (13 fold) and iWAT (3 fold) than that of skeletal muscle or BAT. VEGFA expression was significantly increased in both of skeletal muscles and iWAT after 6 weeks of exercise training. Unlike skeletal muscle and iWAT, VEGFA expression was dramatically decreased in eWAT after training (Fig. 2A). Although the induction of VEGF in skeletal muscle was increased about 2 fold after exercise training, Flk-1 expression was not changed. Instead, exercise training dramatically decreased the expression of Flk-1 in eWAT (Fig. 2B).

\section{Exercise training regulates Ang expression in WAT}

Angiopoietin tightly regulates angiogenesis and vascular integrity. The expression level of Ang1 in control group was relatively higher in eWAT (2 fold) and iWAT (3 fold) than that of skeletal muscle or BAT, whereas Ang2 expression in control group was 2 times higher in iWAT than those of other tissues (Fig. 3A, B). Af- ter 6 weeks of exercise training, Ang 1 expression was significantly reduced in only iWAT (Fig. 3A). On the other hands, Ang2 expression was significantly induced in eWAT after exercise training (Fig. 3B). However, Tie2 expression was not altered after exercise training (Fig. 3C).

\section{PDGFR $\beta$ expressions are altered in eWAT after exercise training}

To determine whether exercise training regulated the expression of PDGF-B and its receptor PDGFR $\beta$, mRNA expression was analyzed with skeletal muscles and adipose tissues after 6 weeks of voluntary wheel running. Similar with the expression levels of VEGFA and Ang1, PDGF-B expression was higher in eWAT (3.6 fold) and iWAT (2.5 fold) than TA in control group (Fig. 4A), however there was no alteration of PDGF-B in adipose tissues after exercise training. Instead, the expression of PDGF-B was significantly increased in Sol after exercise training (Fig. 4A), but the
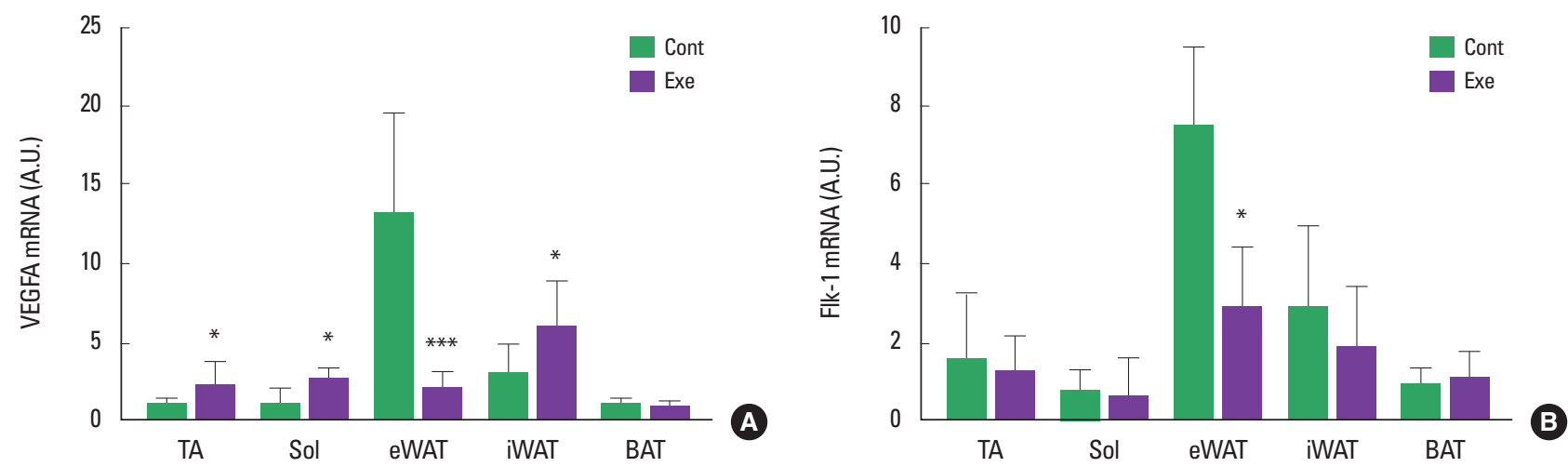

Fig. 2. Expression of vascular endothelial growth factor A (VEGFA), and Flk-1 in skeletal muscles and adipose tissues after exercise training. The expression of VEGFA (A) and Flk-1 (B) were assessed by reverse transcription-polymerase chain reaction. Each value was normalized to GAPDH. Bars represent the means and error bars represent standard deviation $(n=8)$. Cont, control group; Exe, exercise group; TA, tibialis anterior; Sol, soleus; eWAT, epididymal white adipose tissue; iWAT, inguinal white adipose tissue; BAT, brown adipose tissue. ${ }^{*} P<0.05,{ }^{* * *} P<0.001$ vs. Cont.
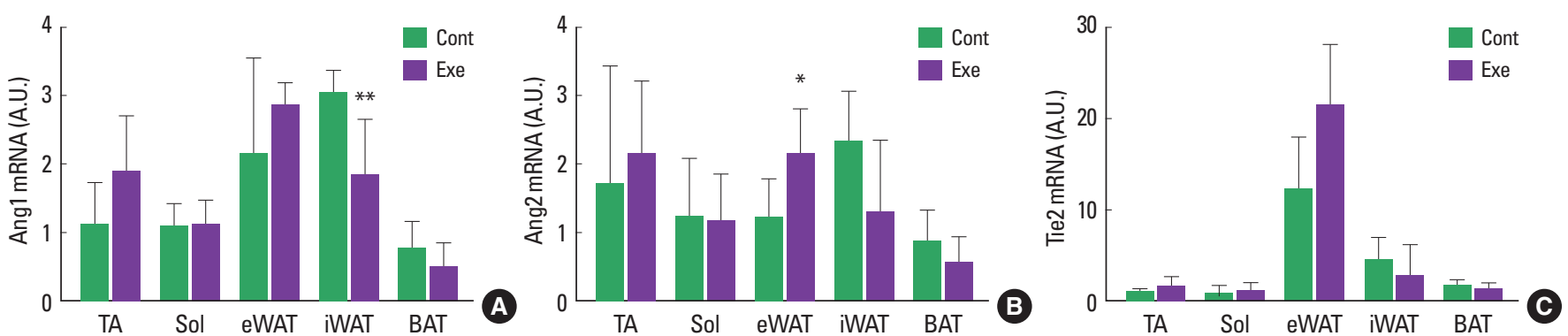

Fig. 3. Expression of Ang1, Ang2, and Tie2 in skeletal muscles and adipose tissues after exercise training. The expression of Ang1 (A), Ang2 (B), and Tie2 (C) were assessed by reverse transcription-polymerase chain reaction. Each value was normalized to GAPDH. Bars represent the means and error bars represent standard deviation $(n=8)$. Cont, control group; Exe, exercise group; TA, tibialis anterior; Sol, soleus; eWAT, epididymal white adipose tissue; iWAT, inguinal white adipose tissue; BAT, brown adipose tissue. ${ }^{*} P<0.05$, ${ }^{* *} P<0.01$ vs. Cont. 

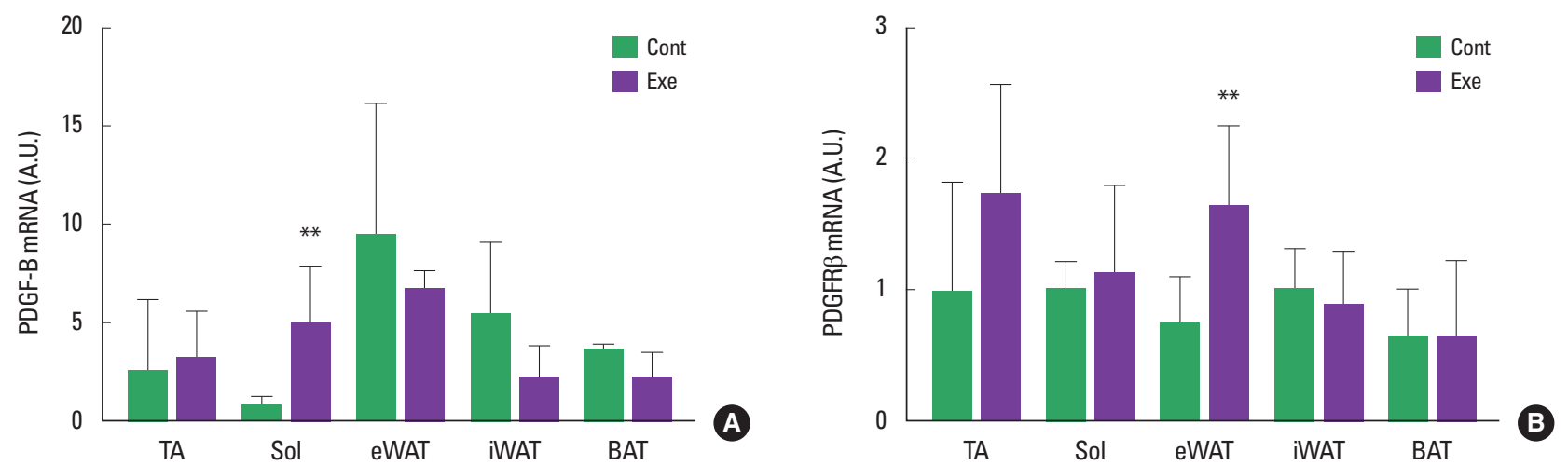

Fig. 4. Expression of platelet-derived growth factor $B$ (PDGF-B) and platelet-derived growth factor receptor $\beta$ (PDGFR $\beta$ ) in skeletal muscles and adipose tissues after exercise training. The expression of PDGF-B $(A)$ and PDGFR $\beta(B)$ were assessed by reverse transcription-polymerase chain reaction. Each value was normalized to GAPDH. Bars represent the means and error bars represent standard deviation $(n=8)$. Cont, control group; Exe, exercise group; TA, tibialis anterior; Sol, soleus; eWAT, epididymal white adipose tissue; iWAT, inguinal white adipose tissue; BAT, brown adipose tissue. ${ }^{* *} P<0.01$ vs. Cont.

expression level of PDGFR- $\beta$ was not changed in Sol after exercise training. Instead, its expression was increased in eWAT after exercise training (Fig. 4B).

\section{DISCUSSION}

It is well known that exercise training regulates angiogenesis by stimulating angiogenic gene expression in heart and skeletal muscle (Erekat et al., 2014; Gustafsson et al., 1999; Lloyd et al., 2003; Trenerry et al., 2011). Besides heart and skeletal muscle, VEGFA-induced vascular remodeling plays a key role in adipose tissue function in systemic glucose homeostasis that impacts on insulin resistance (Sung et al., 2013). Adipose tissue responses differently to energy intake or expenditure and its mass is reduced by exercise training since fatty acid from adipose tissue is utilized during exercise as fuel (Horowitz, 2003). However, it has not been clear whether angiogenic gene expression is altered in reduced adipose tissue after exercise training. To identify the expression level of angiogenic genes after exercise training, mice were performed voluntary wheel running for 6 weeks. Although treadmill or swimming exercise that generates reproducible speeds or distances is regarded as a standardized exercise protocol for rodents, electrical stimulus or environmental stress on mouse for the force active movement might jeopardize the effects of exercise. Therefore, voluntary wheel running exercise was applied to avoid of additional stresses except exercise in the current study.

Previous studies showed that exercise training with voluntary wheel reduced body weight and adiposity in diet-induced obese mice as well as normal diet treated lean mice (Reynolds et al., 2015). Consistently, body weight was significantly decreased with the reduction of WAT weights in Exe after 6 weeks of voluntary wheel running in this study (Fig. 1). The reduction of adipose tissue mass after exercise is attributed to the hypotrophy of adipocytes. Hypotrophy of white adipocytes in obese individuals after exercise training results from lipolysis regulated by hormone sensitive lipase and adipose triglyceride lipase (Ogasawara et al., 2010; Ogasawara et al., 2012). After confirming that the weights of eWAT and iWAT were reduced in exercise group (Fig. 1B), angiogenic gene expression was analyzed.

Exercise training increased VEGFA expression in heart and skeletal muscle. Swimming exercise for 15 days increased cardiac vascularization and swimming exercise combined VEGF treatment accelerated angiogenic process in heart (Efthimiadou et al., 2004). Indeed, both single exercise and endurance training upregulated VEGFA expression in skeletal muscle (Breen et al., 1996; Lloyd et al., 2003). However, upregulated VEGF was downregulated to normal level after exercise training (Lloyd et al., 2003). Although, increased fat mass showed positive correlation with VEGFA expression (Miyazawa-Hoshimoto et al., 2005), it has not been intensively studied whether VEGFA expression is altered in downsized adipose tissue after exercise training. After 6 weeks of voluntary wheel running exercise in this study, VEGFA expression was upregulated in TA and Sol as described previously, whereas its expression was dramatically downregulated in eWAT. Unlike eWAT, VEGFA expression was increased in iWAT despite the reduction of its mass after exercise training (Fig. 2A). VEGF is expressed in mature adipocytes of rodents and its expression is higher in visceral fat than subcutaneous fat (Fain et al., 2004; Miyazawa-Hoshimoto et al., 2005). Furthermore, VEGFA secretion from 3T3L-1 cells (a cell line cell of preadipocytes) kept being in- 
creased on the way of differentiation, indicating that lipid accumulation in adipocytes is related with VEGFA translation (Miyazawa-Hoshimoto et al., 2005). Therefore, the downregulation of VEGFA expression in eWAT after exercise training might be caused by the reduction of adipocyte size in eWAT. At least in myocytes, VEGFA expression is mediated by peroxisome proliferator-activated receptor- $\gamma$ coactivator 1 alpha (Chinsomboon et al., 2009), however, it has not been identified the key regulator of VEGFA expression in adipose tissue after exercise. Exercise also suppressed the expression of Flk-1, VEGFA receptor. Since endothelial cell survival and growth were tightly regulated by Flk-1 (Ferrara et al., 2003), downregulation of both VEGFA and Flk-1 in eWAT after exercise might be a physiologic response to help regression of blood vessel depending on the reduction of adipose tissue mass. Therefore, regulators of VEGFA and the density or number of blood vessel in adipose tissue after exercise training should be analyzed to explain the physiological meaning of VEGFA and Flk-1 downregulations in future studies.

In iWAT, Ang1, instead of VEGFA, was downregulated after exercise training. Ang1 is responsible for the vascular maturation and integrity by recruiting pericytes and vascular remodeling by enhancing angiogenesis via Tie2 receptor (Chae et al., 2000; Cho et al., 2005; Jung et al., 2009; Park et al., 2009; Shin et al., 2010; Smith et al., 2012; Suri et al., 1998). Compared with VEGFA, the function of Ang1 in adipose tissue is not clear. Differentiated 3T3L-1 cells expressed Ang1 and TNP-470 treatment in ob/ob mouse reduced adipose tissue mass accompanied with downregulation of Ang1 expression (Dallabrida et al., 2003). It indicates that Ang1 expression in adipocytes diminished by reduction of fat mass. Therefore, the downregulation of Ang1 in iWAT after exercise training might be caused by the reduction of fat mass and it might be related with the regression of blood vessel. But it is not still clear why Ang1 expression was altered only in iWAT, not eWAT. Although VEGFA and Ang1 are all important for the generation of new blood vessel, they might contribute to fat depot specifically for the regression of blood vessel upon the need of fat mass reduction. For the confirmation of fat depot specific function of Ang1 and VEGFA on vessel regression, the vasculature of adipose tissues after exercise training should be investigated with adipocyte specific VEGFA or Ang1 deficient mouse in future. On the other hand, Ang2 was upregulated in eWAT after exercise training. Although inflammation is known to be a key regulator of Ang2 that is an antagonist of Ang1 (Felcht et al., 2012; Fiedler et al., 2006; Gale et al., 2002; Li et al., 2015), it was recently reported that Ang2 had a pro-angiogenic function in adipose tis- sues. Adipose tissue specific overexpression of Ang2 using adiponectin promoter increased vascularization with induction of VEGFA during WAT expansion induced by high fat diet treatment. Additionally, Ang2 reduced tumor necrosis factor alpha expression in WAT under high fat diet treatment, indicating that Ang2 improved angiogenesis and inflammation in obese WAT (An et al., 2017). Therefore, Ang2 upregulation in eWAT after exercise might be a compensatory response for the reduction of VEGFA to maintain a certain number of blood vessels. Also VEGF induction in iWAT might results from the induction of Ang1 for compensation. To confirm the compensatory response in WATs, it is necessary to analyze of the alteration of these gene expressions from adipose tissue specific Ang1 and VEGFA deficient mice in future studies.

PDGF-B expression was increased in Sol and this finding is consistent with previous study (Trenerry et al., 2011) but its expression was comparable in adipose tissues. Instead, PDGFR $\beta$ expression was significantly upregulated in eWAT after exercise training. PDGFR- $\beta$ is generally expressed on smooth muscle cells and pericytes (Levéen et al., 1994; Soriano, 1994). At least in adipose tissue, PDGFR $\beta^{+}$pericytes are regarded as one of adipocyte precursor cells because they are able to turn into mature adipocytes (Tang et al., 2008). Recently, the function of PDGFR- $\beta$ in adipose tissue was uncovered. PDGFR- $\beta$ knock-out mouse attenuated pericytes detachment in WAT with decrease in adipocytes size and enhanced glucose metabolism and energy expenditure (Onogi et al., 2017). After 6 weeks of exercise, there was no change in PDGF-B expression in adipose tissues and it indicates that PDGFR- $\beta$ signaling is not activated after exercise training. Exercise training suppresses the differentiation of stromal vascular fraction of adipose tissue into mature adipocytes (Sakurai et al., 2010). Therefore, upregulation of PDGFR $\beta$ after exercise might reflex the accumulation of PDGFR $\beta^{+}$pericytes only in downsized eWAT that highly depends on adipocytes hyperplasia for expansion, not iWAT that expands its mass through adipocyte hypertrophy (Wang et al., 2013).

Collectively, exercise training with voluntary wheel running altered angiogenic gene expression in downsized WATs. For further studies of its physiological meaning and biological mechanism, the origin of VEGFA, Angs, PDGF-B and their receptors should be analyzed in adipose tissue with reporter mice and orchestration of angiogenic factors after exercise training need to be studies with adipose specific knock-out mouse in near future. 


\section{CONFLICT OF INTEREST}

No potential conflict of interest relevant to this article was reported.

\section{REFERENCES}

An YA, Sun K, Joffin N, Zhang F, Deng Y, Donzé O, Kusminski CM, Scherer PE. Angiopoietin-2 in white adipose tissue improves metabolic homeostasis through enhanced angiogenesis. Elife 2017;6. pii: e24071.

Breen EC, Johnson EC, Wagner H, Tseng HM, Sung LA, Wagner PD. Angiogenic growth factor mRNA responses in muscle to a single bout of exercise. J Appl Physiol (1985) 1996;81:355-361.

Carmeliet P, Ferreira V, Breier G, Pollefeyt S, Kieckens L, Gertsenstein M, Fahrig M, Vandenhoeck A, Harpal K, Eberhardt C, Declercq C, Pawling J, Moons L, Collen D, Risau W, Nagy A. Abnormal blood vessel development and lethality in embryos lacking a single VEGF allele. Nature 1996;380:435-439.

Chae JK, Kim I, Lim ST, Chung MJ, Kim WH, Kim HG, Ko JK, Koh GY. Coadministration of angiopoietin-1 and vascular endothelial growth factor enhances collateral vascularization. Arterioscler Thromb Vasc Biol 2000;20:2573-2578.

Chinsomboon J, Ruas J, Gupta RK, Thom R, Shoag J, Rowe GC, Sawada N, Raghuram S, Arany Z. The transcriptional coactivator PGC-1 $\alpha$ mediates exercise-induced angiogenesis in skeletal muscle. Proc Natl Acad Sci U S A 2009;106:21401-21406.

Cho CH, Kim KE, Byun J, Jang HS, Kim DK, Baluk P, Baffert F, Lee GM, Mochizuki N, Kim J, Jeon BH, McDonald DM, Koh GY. Long-term and sustained COMP-Ang1 induces long-lasting vascular enlargement and enhanced blood flow. Circ Res 2005;97:86-94.

Cho CH, Koh YJ, Han J, Sung HK, Jong Lee H, Morisada T, Schwendener RA, Brekken RA, Kang G, Oike Y, Choi TS, Suda T, Yoo OJ, Koh GY. Angiogenic role of LYVE-1-positive macrophages in adipose tissue. Circ Res 2007;100:e47-e57.

Dallabrida SM, Zurakowski D, Shih SC, Smith LE, Folkman J, Moulton KS, Rupnick MA. Adipose tissue growth and regression are regulated by angiopoietin-1. Biochem Biophys Res Commun 2003;311:563-571.

Efthimiadou A, Asimakopoulos B, Nikolettos N, Giatromanolaki A, Sivridis E, Lialiaris TS, Papachristou DN, Kontoleon E. The angiogenetic effect of intramuscular administration of VEGF on muscle. The influence of exercise on angiogenesis. In Vivo 2004;18:825-829.

Erekat NS, Al-Jarrah MD, Al Khatib AJ. Treadmill exercise training improves vascular endothelial growth factor expression in the cardiac muscle of type I diabetic rats. Cardiol Res 2014;5:23-29.

Fagiani E, Christofori G. Angiopoietins in angiogenesis. Cancer Lett 2013;
328:18-26.

Fain JN, Madan AK, Hiler ML, Cheema P, Bahouth SW. Comparison of the release of adipokines by adipose tissue, adipose tissue matrix, and adipocytes from visceral and subcutaneous abdominal adipose tissues of obese humans. Endocrinology 2004;145:2273-2282.

Felcht M, Luck R, Schering A, Seidel P, Srivastava K, Hu J, Bartol A, Kienast Y, Vettel C, Loos EK, Kutschera S, Bartels S, Appak S, Besemfelder E, Terhardt D, Chavakis E, Wieland T, Klein C, Thomas M, Uemura A, Goerdt S, Augustin HG. Angiopoietin-2 differentially regulates angiogenesis through TIE2 and integrin signaling. J Clin Invest 2012;122:1991-2005.

Ferrara N, Carver-Moore K, Chen H, Dowd M, Lu L, O'Shea KS, Powell-Braxton L, Hillan KJ, Moore MW. Heterozygous embryonic lethality induced by targeted inactivation of the VEGF gene. Nature 1996; 380:439-442.

Ferrara N, Gerber HP, LeCouter J. The biology of VEGF and its receptors. Nat Med 2003;9:669-676.

Fiedler U, Reiss Y, Scharpfenecker M, Grunow V, Koidl S, Thurston G, Gale NW, Witzenrath M, Rosseau S, Suttorp N, Sobke A, Herrmann M, Preissner KT, Vajkoczy P, Augustin HG. Angiopoietin-2 sensitizes endothelial cells to TNF-alpha and has a crucial role in the induction of inflammation. Nat Med 2006;12:235-239.

Gale NW, Thurston G, Hackett SF, Renard R, Wang Q, McClain J, Martin C, Witte C, Witte MH, Jackson D, Suri C, Campochiaro PA, Wiegand SJ, Yancopoulos GD. Angiopoietin-2 is required for postnatal angiogenesis and lymphatic patterning, and only the latter role is rescued by Angiopoietin-1. Dev Cell 2002;3:411-423.

Gerber HP, Hillan KJ, Ryan AM, Kowalski J, Keller GA, Rangell L, Wright BD, Radtke F, Aguet M, Ferrara N. VEGF is required for growth and survival in neonatal mice. Development 1999;126:1149-1159.

Gustafsson T, Puntschart A, Kaijser L, Jansson E, Sundberg CJ. Exerciseinduced expression of angiogenesis-related transcription and growth factors in human skeletal muscle. Am J Physiol 1999;276(2 Pt 2):H679H685.

Horowitz JF. Fatty acid mobilization from adipose tissue during exercise. Trends Endocrinol Metab 2003;14:386-392.

Jung YJ, Kim DH, Lee AS, Lee S, Kang KP, Lee SY, Jang KY, Sung MJ, Park SK, Kim W. Peritubular capillary preservation with COMP-angiopoietin-1 decreases ischemia-reperfusion-induced acute kidney injury. Am J Physiol Renal Physiol 2009;297:F952-F960.

Lange S, Heger J, Euler G, Wartenberg M, Piper HM, Sauer H. Platelet-derived growth factor $\mathrm{BB}$ stimulates vasculogenesis of embryonic stem cell-derived endothelial cells by calcium-mediated generation of reactive oxygen species. Cardiovasc Res 2009;81:159-168.

Levéen P, Pekny M, Gebre-Medhin S, Swolin B, Larsson E, Betsholtz C. 
Mice deficient for PDGF B show renal, cardiovascular, and hematological abnormalities. Genes Dev 1994;8:1875-1887.

Li L, Qian L, Yu ZQ. Serum angiopoietin-2 is associated with angiopathy in type 2 diabetes mellitus. J Diabetes Complications 2015;29:568-571.

Lloyd PG, Prior BM, Yang HT, Terjung RL. Angiogenic growth factor expression in rat skeletal muscle in response to exercise training. Am J Physiol Heart Circ Physiol 2003;284:H1668-H1678.

Maisonpierre PC, Suri C, Jones PF, Bartunkova S, Wiegand SJ, Radziejewski C, Compton D, McClain J, Aldrich TH, Papadopoulos N, Daly TJ, Davis S, Sato TN, Yancopoulos GD. Angiopoietin-2, a natural antagonist for Tie2 that disrupts in vivo angiogenesis. Science 1997;277:55-60.

Miyazawa-Hoshimoto S, Takahashi K, Bujo H, Hashimoto N, Yagui K, Saito Y. Roles of degree of fat deposition and its localization on VEGF expression in adipocytes. Am J Physiol Endocrinol Metab 2005;288: E1128-E1136.

Ogasawara J, Nomura S, Rahman N, Sakurai T, Kizaki T, Izawa T, Ishida $\mathrm{H}$, Haga S, Ohno H. Hormone-sensitive lipase is critical mediators of acute exercise-induced regulation of lipolysis in rat adipocytes. Biochem Biophys Res Commun 2010;400:134-139.

Ogasawara J, Sakurai T, Kizaki T, Ishibashi Y, Izawa T, Sumitani Y, Ishida H, Radak Z, Haga S, Ohno H. Higher levels of ATGL are associated with exercise-induced enhancement of lipolysis in rat epididymal adipocytes. PLoS One 2012;7:e40876.

Onogi Y, Wada T, Kamiya C, Inata K, Matsuzawa T, Inaba Y, Kimura K, Inoue $\mathrm{H}$, Yamamoto S, Ishii $Y$, Koya D, Tsuneki H, Sasahara M, Sasaoka T. PDGFR $\beta$ regulates adipose tissue expansion and glucose metabolism via vascular remodeling in diet-induced obesity. Diabetes 2017; 66:1008-1021

Park BH, Jang KY, Kim KH, Song KH, Lee SY, Yoon SJ, Kwon KS, Yoo WH, Koh YJ, Yoon KH, Son HH, Koh GY, Kim JR. COMP-Angiopoietin-1 ameliorates surgery-induced ischemic necrosis of the femoral head in rats. Bone 2009;44:886-892.

Reynolds TH 4th, Banerjee S, Sharma VM, Donohue J, Couldwell S, Sosinsky A, Frulla A, Robinson A, Puri V. Effects of a high fat diet and voluntary wheel running exercise on cidea and cidec expression in liver and adipose tissue of mice. PLoS One 2015;10:e0130259.

Rupnick MA, Panigrahy D, Zhang CY, Dallabrida SM, Lowell BB, Langer $\mathrm{R}$, Folkman MJ. Adipose tissue mass can be regulated through the vasculature. Proc Natl Acad Sci U S A 2002:99:10730-10735.

Sakurai T, Endo S, Hatano D, Ogasawara J, Kizaki T, Oh-ishi S, Izawa T, Ishida $\mathrm{H}$, Ohno $\mathrm{H}$. Effects of exercise training on adipogenesis of stromal-vascular fraction cells in rat epididymal white adipose tissue. Acta Physiol (Oxf) 2010;200:325-338.

Shalaby F, Rossant J, Yamaguchi TP, Gertsenstein M, Wu XF, Breitman ML, Schuh AC. Failure of blood-island formation and vasculogenesis in Flk-1-deficient mice. Nature 1995;376:62-66.

Shin HY, Lee YJ, Kim HJ, Park CK, Kim JH, Wang KC, Kim DG, Koh GY, Paek SH. Protective role of COMP-Ang1 in ischemic rat brain. J Neurosci Res 2010;88:1052-1063.

Smith AH, Kuliszewski MA, Liao C, Rudenko D, Stewart DJ, Leong-Poi $H$. Sustained improvement in perfusion and flow reserve after temporally separated delivery of vascular endothelial growth factor and angiopoietin-1 plasmid deoxyribonucleic acid. J Am Coll Cardiol 2012; 59:1320-1328.

Soriano P. Abnormal kidney development and hematological disorders in PDGF beta-receptor mutant mice. Genes Dev 1994;8:1888-1896.

Sung HK, Doh KO, Son JE, Park JG, Bae Y, Choi S, Nelson SM, Cowling R, Nagy K, Michael IP, Koh GY, Adamson SL, Pawson T, Nagy A. Adipose vascular endothelial growth factor regulates metabolic homeostasis through angiogenesis. Cell Metab 2013;17:61-72.

Suri C, Jones PF, Patan S, Bartunkova S, Maisonpierre PC, Davis S, Sato TN, Yancopoulos GD. Requisite role of angiopoietin-1, a ligand for the TIE2 receptor, during embryonic angiogenesis. Cell 1996;87:1171-1180. Suri C, McClain J, Thurston G, McDonald DM, Zhou H, Oldmixon EH, Sato TN, Yancopoulos GD. Increased vascularization in mice overexpressing angiopoietin-1. Science 1998;282:468-471.

Tang W, Zeve D, Suh JM, Bosnakovski D, Kyba M, Hammer RE, Tallquist $\mathrm{MD}$, Graff JM. White fat progenitor cells reside in the adipose vasculature. Science 2008;322:583-586.

Trenerry MK, Della Gatta PA, Larsen AE, Garnham AP, Cameron-Smith D. Impact of resistance exercise training on interleukin-6 and JAK/ STAT in young men. Muscle Nerve 2011;43:385-392.

Wang QA, Tao C, Gupta RK, Scherer PE. Tracking adipogenesis during white adipose tissue development, expansion and regeneration. Nat Med 2013;19:1338-1344. 